\title{
Prevalence and Determinants of Trachomatous Trichiasis towards Elimination of Trachoma in Ethiopia: A Systematic Review and Meta- Analysis
}

Daniel Geleta ( $\nabla$ daninagaa2009@gmail.com )

Jimma University College of Public Health and Medical Sciences https://orcid.org/0000-0001-6516-0185

Netsanet Workneh

Jimma Institute of Health Sciences

Research

Keywords: elimination, meta-analysis, pattern, prevalence, review, trachoma, trichiasis

Posted Date: August 11th, 2021

DOI: https://doi.org/10.21203/rs.3.rs-743732/v1

License: () (7) This work is licensed under a Creative Commons Attribution 4.0 International License. Read Full License 


\section{Abstract}

Background: Trachomatous Trichiasis is a preventable and treatable late stage of trachoma infection, mainly exacerbating the condition of poor and marginalized people. Given the hurtful nature of the infection, many countries, including Ethiopia, lack coherent data on the status of the problem toward its targeted time of elimination. Hence, this systematic review and meta-analysis aimed to provide a comprehensive overview of the prevalence and determinants of trachomatous trichiasis towards the elimination of trachoma in Ethiopia.

Methods: Based on the predefined criteria, electronic database searches on the peer-reviewed journal papers of an English version were reviewed on the prevalence and determinants of trachomatous trichiasis among the adult population in Ethiopia from January 2015 to December 2020 . After reviewing the quality of the individual sources of evidence by three reviewers, the data items were extracted using a locally devised charting form. Data were synthesized qualitatively and quantitatively in terms of publication year, design, study participants, and outcome of interest. Finally, quantitative results were pooled, explored for sources of variation, tested for a potential source of influence of prevalence estimates and publication bias in the statistical meta-analysis using STATA version-16 software.

Result: After the exclusion of 121 duplicates, 108 extraneous titles \& abstracts, and removal of three articles for the reasons detected on full-text screening, ten eligible studies were included for analysis. All the included studies were cross-sectional studies that took prevalence as the main outcome of interest. Accordingly, the overall pooled prevalence of Trachomatous trichiasis was $1.80 \%(95 \% \mathrm{Cl}=1.15,2.44)$ while an individual prevalence estimate of the studies ranged from $0.5 \%(95 \% \mathrm{Cl}=0.42,0.60)$ to $3.9 \%(95 \% \mathrm{Cl}=3.82,3.98)$. On subgroup analysis, the highest $[3.76 \%(95 \% \mathrm{Cl}=3.20,4.41)]$ and the lowest $[0.5 \%$ $(95 \% \mathrm{Cl}=0.42,0.60)]$ prevalence were respectively reported in Gambella and Somalia. The trend of the prevalence has demonstrated unstable pattern, while there were no published studies on the determinants of trachoma trichiasis among adult over the specified period of the review.

Conclusion: The prevalence of TT was significantly higher than the elimination threshold in all regions of Ethiopia, needing further implementation to facilitate roads toward the elimination.

Trail registration: CRD42021260802

\section{Introduction}

Trachoma is a neglected tropical disease that affects poor and marginalized populations around the world. The disease caused by infection with Chlamydia trachomatis that propagates through personal contacts and by flies that have been in contact with the discharge of an infected member of a human community. Characteristically, it causes inflammation in early childhood in the conjunctiva with subsequent scarring, corneal opacity, and blindness in adult aged $\geq 15$ years [ $1-5]$. For the sake of simplicity and cost-effectiveness, the diagnosis and characteristics of trachoma infection were established using a simplified World Health Organization (WHO) grading scale. Accordingly, follicular inflammation (TF), intense trachomatous inflammation, trachomatous scarring, trachomatous trichiasis (TT), and corneal opacity are five distinct stages in severity order. Of these stages, TT is a spectrum of the disease with cicatricial entropion in the upper lids and usually occurred after the active trachoma was controlled. The condition commonly causes a poignant problem to adult population of age $\geq 15$ years, but rarely diagnosed in children $[5,6]$.

For the elimination of blinding trachoma in high-burden countries, WHO has been advocating and leading a harmonious implementation of surgery, antibiotics, facial cleanliness \& an environmental improvement (SAFE) strategy that supported simultaneously by a regular survey and operational researches. However, despite having been prevented or cured relatively easily using these strategies, trachoma has continued to be the leading infectious cause of blindness globally [11, 12]. Different study reports have also publicized that 200 million people are at the risk of suffering trachoma, while 1.8 million people had confronted a visual loss; 450 thousand people had suffered irreversible blindness, and 3.2 million people needed TT surgery to avoid blindness and the subsequent burden. The burden of trachoma on the affected individuals and communities can be measured by an impact assessment using the prevalence of TF in children aged 1 to 9 years, TT in $\geq 15$ years, and the overall prevalence among the total population. Moreover, the regular summarization of data from prevalence, surveys, and researches contributes to indicate the propensity of a country towards the elimination of trachoma [14-16]. Affectionately, literature notified that WHO used the summarized data for the announcement of several countries that were well on their way to eliminate trachoma, and consequently the countries on the trail of a global alliance with a prevalence of TT $<1$ case per 1000 of $\geq 15$ years and TF $<5 \%$ in children aged 1 to 9 years were received a certificate of trachoma elimination. On the other hand, many countries including African countries have shown a steady kick-down of trachoma due to two main factors; sub-optimal evidence generation and poorly controlled trachoma determinants like sanitation, overcrowding, and poverty [8, 16, 17].

To entail this international agenda, Ethiopia has established a taskforce, and aggressively been implementing numerous trachoma elimination activities including survey and operational researches. This taskforce used to regularly summarize data and monitor the progress of implementation to ensure the decline of the prevalence of TT below the elimination threshold. However, trachoma has continued to account for blindness and higher prevalence (6.2\% of TT) in a population aged 15 \& older years in the country in different regions, especially in the disadvantaged populations $[3,4,18]$.

Generally, individual researches on trachoma, generating summarized data on prevalence, and the conduct of detailed observational studies were premeditated to contribute to the elimination of trachoma. However, there were no summarized data, particularly on the contemporary prevalence pattern and determinants of TT in the Ethiopian population aged 15 years and older. Therefore, this systematic review and meta-analysis has aimed to contemporize prevalence and determinants of TT among adult population in Ethiopia from January 2015 to December 2020. During the analysis of prevalence, the current administrative subdivision of Ethiopia delineated with ten ethno-linguistic territoriality; namely Afar, Amhara, Benshangul- Gumuz, Gambela, Harari, Oromia, Sidama, Somali, south nation's nationalities \& peoples region (SNNPR) \& Tigray, and two chartered cities (Addis Ababa \& Dire Dawa was used to characterize the prevalence [19]. 


\section{Methods}

\section{Protocol and registration}

The plan of this review was developed based on the guidelines of the center for review and discrimination [20], and based on the metaanalysis report of observational studies in the epidemiological guidelines [21]. Similarly, the report of the way studies were selected followed the guidance of preferred reporting items for systematic review and meta-analysis protocol (PRISMA- P) [22]. The study protocol was determined prior to commencement and registered in the PROSPERO-International prospective register of systematic review. Consequently, the Prospero has endorsed an identified \& recognized number as CRD42021260802 after some check-outs of similar existing review in their website.

\section{Eligibility criteria}

Peer-reviewed journal papers were included if they were conducted in Ethiopia and published between the period of 2015-2020 in publishing journals, written in English, and involved adult participants. Original articles of quantitative, qualitative, or mixed study design containing data reports of prevalence and determinants of trachoma among adults were included regardless of their settings. Papers were excluded if they did not fit into the inclusion criteria of the study (should contain numerator and denominators of the prevalence for estimation of effect size). On the other hands, narratives, commentaries, implementation reports, and essays were excluded from the review. Periodically, the review included only five recent years following the widest scale-up of trachoma intervention activities by different stakeholders in these years than ever to succeed with WHO Get 2020 alliance. The review is also limited to specified geographic study areas because of great variability in epidemiologic pattern of the infection that follows the intervention momentum of each locality [23].

\section{Information sources, search strategies and selection of sources of evidence}

\section{Original peer-}

reviewed articles published in English language journals from January 2015 to December 2020 were obtained from systematic searches of different electronic that include (PubMed, Google scholar, Scopus, HINARI, web of science, and worldwide Science) with full text in June 2021. The final search strategy for PubMed was indicated in Table 1.

Table 1 search approach and data extraction format

\begin{tabular}{|c|c|}
\hline Information focus & MeSH heading and search combinations \\
\hline Study Subject & Adult or $\geq 15$ years age or Household head or Old ages \\
\hline Outcome of interest & 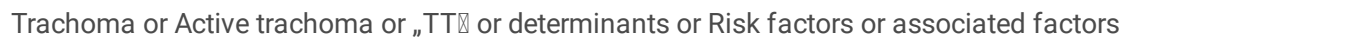 \\
\hline Study type & Epidemiology or Prevalence or trend \\
\hline Study design & Cross-sectional or Observational or Longitudinal or Survey or census not (Review or Case report or Case series) \\
\hline Location & $\begin{array}{l}\text { Ethiopia or Afar, orAmhara,orBenshangul-Gumuz, or Gambela, or Harari, or } \quad \text { Oromia, or Sidama, } \\
\text { or Somali, or SNNPR or Tigray, or Addis Ababa or Dire Dawa }\end{array}$ \\
\hline
\end{tabular}

All identified articles from the searches were saved in a clipboard and transferred to reference manager software (Zotero) where the files were externally opened and systematically reviewed for screenings. The participants, context, concept, outcome, and study design framework were used to establish eligibility criteria [20]. In order to be included, original peer-reviewed articles had to meet five criteria. First, the study considered prevalence among the adult population. Second, the focus of the study was determinants of the prevalence of TT without co-morbidity. Studies that simultaneously studied the prevalence and the determinants of trachoma and other infections were excluded due to our inability to ascertain the independent effect of the factor on the pattern of the outcome. Likewise, studies that considered prevalence among different (non-adult) population groups were excluded. Third, the studies conducted in urban, suburban, semi-rural, and rural settings were included, but all studies that clearly stated they were covered all regions of the country were excluded. Fourth, at least one of the outcomes measured or findings reported in the study was included. Fifth, only peer-reviewed articles written in English that describe original cross-

sectional and observational methods of research were considered. The grey literature, narratives, commentaries, or other document types such as reports, essa' In applying the eligibility criteria, two reviewers [Daniel Geleta (DG) with epidemiological experience and Netsanet Workneh (NW) with medical experience] have reviewed these articles for selection. The first choice was from the title and abstract selection, and the second was from the full text selection. Any differences between the two authors on study choice and data extraction were resolved through discussion and consensus.

\section{Data charting and data items}

A data-charting form was jointly developed by two reviewers to determine which variables to extract. The two reviewers independently charted the data, discussed the results, and continuously updated the data-charting form in an iterative process. After the selection of articles, first author(s), year of publication, region, study purpose, study design, characteristics of participants (adults), the sample size, measurement methods, and outcomes measured and analyzed outcomes were recorded in a spreadsheet as in Table 2.

\section{Study quality and risk of bias assessment}


The authors used the Newcastle-Ottawa quality assessment tool scale to evaluate the quality of the studies for cross-sectional studies

[24] in consultation with an existing tool for risk of bias assessment in prevalence studies on evidence of interrater agreement

[25]. The tool has three compartmental indicators. The first section is graded out of five stars and assesses the quality of the methodology of a study. The second part of the tool is graded out of three stars and assesses the comparability of the studies. The last part of the tool is graded from two stars and measures the quality of the original articles with respect to their statistical analyses. Cross-sectional studies with medium (fulfilling $50 \%$ of quality assessment criteria) and high quality ( $\geq 6$ out of 10 scales) scores were included for analysis. The first author appraised the quality of the included studies and obtained validation from the second and third author. Similarly, an existing quality assessment tool was considered for observational studies for the assessment of the quality [26].

\section{Data synthesis and analysis}

A narrative account of the included studies was prepared to present the pooled prevalence and determinants of TT. After the pooled prevalence, the pattern of the prevalence was displayed by line graph to display the relation between prevalence and publication year. In the graph, the prevalence of the infection was arranged from the earlier to the latest year of publication to implicate

the existing patterns of the infection. Further, the studies were grouped specifically by country administrative territory (region) to indicate the heterogeneity of the studied across the region.

\section{Statistical meta-analysis}

The pooled prevalence of TT was calculated using stata- 16 software for the current meta-analysis in fixed-

effects or random- effects model. A forest plot was used to visualize the individual and pooled prevalence of the studies with their corresponding $95 \%$ Confidence Interval $(\mathrm{Cl})$ for studies combined based on their methodological similarities. The statistical heterogeneity values of the included studies were assessed by Q-static test \& $I^{2}$ statistics, and their corresponding $95 \% \mathrm{Cl}$ [28]. Having four quartiles of heterogeneity levels, the reviewers used a considerable heterogeneity for the values of $75-100 \%$ quartiles. The fixed-effects model was indicated for the data that demonstrated the heterogeneity of values of two lower quartiles and the random-effects model otherwise. Based on the individual study prevalence weight contributed to the pooled prevalence, Meta regression was conducted to show trends of the TT for review years. Subgroup analysis was also performed using region, sample size and year of publication to detect heterogeneity, followed by meta-regression to explore potential sources of heterogeneity. Finally, investigation of sensitivity was conducted through a serial exclusion of each study from the meta-analysis to discover the impact of every included study on heterogeneity. Similarly, a reporting and publication bias by a funnel plot and potential source of publication bias by Bigg『s \& Egger『s test.

\section{Results}

\section{Search results and selected source of evidence}

The searches of the electronic databases hit a total of 253 records (Pubmed: 134, worldwide science116 and others 3 ). Of these, a total of 132 duplicates were removed before a stage of titles and abstracts screening at which 121 studies were excluded. At the stage of title and abstract screening 108 articles were removed, leaving only 13 studies for the full-text assessment. Hereafter, we retrieved a total of 13 full-text articles from our different libraries, and the full-text screening stage led to 10 potential articles relevant to our review. There have been no additional articles excluded after full-text assessment for reasons as mentioned within the flowchart (Figure 1). During the process of removal and exclusion, the main reasons were found to be the focus of the study [29- 36], the site of the study [32,37-40], and the target study population [31,33-40]. To this end, our full data evaluation accommodated 13 articles, whereof three articles were excluded for target population and irrelevancy of the content [42,46,47]. Finally, ten articles were doomed for quality appraisal, data abstraction, and narrative account and meta-analysis stages [18, 48-56]. For ease of data management, the data from the included studies were summarized on the bases of the first author, year of publication, region of study, study purpose, study design, sample size, response rate, study outcome (prevalence \& determinant), outcomes and outcome analyzed (Table 2).

Figure 1PRISMA flow chart to illustrate the process by which articles were selected or rejected Description of included studies

Earlier studies of the included five articles were published in 2016[48-52] while the remaining three and two studies were published respectively in 2018[5355]\& 2019[18,56].Publications were distributed across the regions, and accordingly two studies were published from Amhara region [18,54]while one article published from Gambela [48], Tigray [49], Beneshangul [50], Somalia [55], Afar [53], SNNPR [52], and Oromia [51] regions with the remaining one study from wider area of the country so has labeled as national level [18]. Most of the included studies(50.0\%) were published in the year 2016 [48-52] while there were no publications obtained and included in the year 2015, 2017 \& 2020 (Figure 2). Regardless of their variation in region, all the included studies were followed a similar protocol to establish the details of their participant population. In each study, a cross-sectional study design without repeated measurements or control groups was used with the primary purpose of estimation of trachoma prevalence (ETP).Finally; the entire reviewed articles contritely didn囚t incorporate determinants of TT among the adult population in the current review period in the study areas shown in Table 2 . The study purposes of all included articles were inspiredwith identificationof prevalence of trachoma using a community-based cross-sectional survey (CBCS). During the process of designing, the amount of sample size varies across

every study. Accordingly, the sample size ranged from 3781[48] to241,139 [18] with no reported response rate for all included studies. In all the articles, data were collected at the household level within areas with a total population of 100 to 250,000 as an evaluation unit. The prevalence of trachoma with the simultaneous analysis of the prevalence of TT and TF were considered as outcomes at every evaluation unit [18,48-56].

\section{Critical appraisal within sources of evidence}


All the included studies were assessed for the quality of respective participant selection approach, outcome of interest, and findings as reported in Table 2. During the process of the assessment, each individual study were identified with the placement of scientific \& appropriate sampling method, adequate sample size, and an appropriate method of data analysis (Annex1).All reviewers appraised every article independently using the pre-prepared format. After completion of the independent work, the appraisal results were compared among reviewer that finally provided with a strong quality rating of value greater than five (>5) for all studies as presented on the right wing of Table 2[18,48-56].

Table 2 individual included studies with critical appraisal of individual sources of evidence

\begin{tabular}{|c|c|c|c|c|c|c|c|c|c|}
\hline First author & $\begin{array}{l}\text { Publicati on } \\
\text { year }\end{array}$ & Region & Study purpose & Study design & Sample size & $\begin{array}{l}\text { Respo nse } \\
\text { rate }\end{array}$ & $\begin{array}{l}\text { Preval ence } \\
(\%)\end{array}$ & Determi nants & Outcomes \\
\hline Abashawlet al[48] & 2016 & $\begin{array}{l}\text { Gambell } \\
\text { a }\end{array}$ & ETP & CBCS & 3,781 & $\begin{array}{l}\text { No } \\
\text { report }\end{array}$ & 3.80 & $\begin{array}{l}\text { Not } \\
\text { included }\end{array}$ & Morbidity \\
\hline Sherif S. et al [49] & 2016 & Tigray & ETP & CBCS & 28,581 & $\begin{array}{l}\text { No } \\
\text { report }\end{array}$ & 1.70 & $\begin{array}{l}\text { Not } \\
\text { included }\end{array}$ & Morbidity \\
\hline $\begin{array}{l}\text { Adamu Y.et al } \\
\text { [50] }\end{array}$ & 2016 & $\begin{array}{l}\text { Benesha } \\
\text { ngul }\end{array}$ & ETP & CBCS & 21,919 & $\begin{array}{l}\text { No } \\
\text { report }\end{array}$ & 1.30 & $\begin{array}{l}\text { Not } \\
\text { included }\end{array}$ & Morbidity \\
\hline Bero B. et al [51] & 2016 & Oromia & ETP & CBCS & 127,357 & $\begin{array}{l}\text { No } \\
\text { report }\end{array}$ & 0.82 & $\begin{array}{l}\text { Not } \\
\text { included }\end{array}$ & Morbidity \\
\hline Adera et al [52] & 2016 & SNNPR & ETP & CBCS & 131926 & $\begin{array}{l}\text { No } \\
\text { report }\end{array}$ & 1972 & $\begin{array}{l}\text { Not } \\
\text { included }\end{array}$ & Morbidity \\
\hline $\begin{array}{l}\text { Negash K. et al } \\
\text { [53] }\end{array}$ & 2018 & Afar & ETP & CBCS & 16,905 & $\begin{array}{l}\text { No } \\
\text { report }\end{array}$ & 1.20 & $\begin{array}{l}\text { Not } \\
\text { included }\end{array}$ & Morbidity \\
\hline Nash S. et al [54] & 2018 & Amhara & ETP & CBCS & 20,849 & $\begin{array}{l}\text { No } \\
\text { report }\end{array}$ & 1.70 & $\begin{array}{l}\text { Not } \\
\text { included }\end{array}$ & Morbidity \\
\hline $\begin{array}{l}\text { Duale A.et al } \\
\text { [55]. }\end{array}$ & 2018 & Somalia & ETP & CBCS & 53467 & $\begin{array}{l}\text { No } \\
\text { report }\end{array}$ & 1.20 & $\begin{array}{l}\text { Not } \\
\text { included }\end{array}$ & Morbidity \\
\hline $\begin{array}{l}\text { Stewart A. et al } \\
\text { [18] }\end{array}$ & 2019 & Amhara & ETP & CBCS & 208,265 & $\begin{array}{l}\text { No } \\
\text { report }\end{array}$ & 3.90 & $\begin{array}{l}\text { Not } \\
\text { included }\end{array}$ & Morbidity \\
\hline Meclod.et al [56] & 2019 & National & ETP & CBCS & 241139 & $\begin{array}{l}\text { No } \\
\text { report }\end{array}$ & 1.90 & $\begin{array}{l}\text { Not } \\
\text { included }\end{array}$ & Morbidity \\
\hline
\end{tabular}

\section{Pooled prevalence of TT}

The overall pooled prevalence of TT among adult population of Ethiopia was $1.8 \%(95 \% \mathrm{Cl}=1.15,2.44)$ with high level and significant heterogeneity $\left(\mathrm{I}^{2}=\right.$ $99.81 \%, \mathrm{p}<0.001)$. Simultaneously, the individual prevalence estimates of each article were observed to range from $0.0 \%(95 \% \mathrm{Cl}=0.42,0.60)$ to $3.9 \%$ $(95 \% \mathrm{Cl}=3.82,3.98)$ while the weight contribution ranged from $9.29 \%$ to $10.11 \%$ for each individual article as indicated by forest plot in Figure 2 .

\section{Contribution of regions and national trend of TT prevalence}

The contribution of each region to the pooled prevalence was significantly deferent. Specifically, Gambella as reported by Abashawl contributed 3.76\% $(95 \% \mathrm{Cl}=3.17,4.41)[48]$ while it was $1.6 \%(95 \% \mathrm{Cl}=1.45,1.75)$ in Tigray and $1.3 \%(95 \% \mathrm{Cl}=1.15,1.46)$ in Beneshangulas reported by studies from Sherif $[49]$ and Adamu [50] respectively. Similarly, prevalence of $0.82 \%(95 \% \mathrm{Cl}=0.77,0.87)$ contributed by oromia reported by $\mathrm{Bero}[51], 1.49 \%(95 \% \mathrm{Cl}=1.43,1.56)$ by Adera in SNNPR [52], 1.4\% (95\% Cl= 0.93, 1.38)by Nagashin Afar [53],1.7\% (95\% Cl=1.53, 1.89) by Nash in Amhara[54], 0.5\% $(95 \% \mathrm{Cl}=0.42,0.60)$ by Duale in Somali [55], 3.9\% $(95 \% \mathrm{Cl}=3.82,3.98)$ by Stewart in Amhara [18], and $1.9 \%(95 \% \mathrm{Cl}=1.84,1.95)$ by Mecleod at national level[56](Figure 2). On the basis of individual studies, the prevalence of TT demonstrated an unstable pattern of change over the five years of the review period. The prevalence had been high in 2016, declined in 2018, but hit the highest record in 2019, and commenced declining in 2019 as portrayed by Figure 3.

\section{Subgroup analysis and investigation of heterogeneity}

Based on the administrative division of the country, subgroup analysis using random-effects model was conducted and explored the level of variations among nine regions (Figure 4). Accordingly, the highest TT prevalence $(3.76 \%(95 \% \mathrm{Cl}=3.20,4.41))$ was observed in $\mathrm{Gambella}$ region, 
followed by the Amhara region with a $3.50 \%(95 \% \mathrm{Cl}=3.42,3.57)$, and the lowest $(0.82 \%(95 \% \mathrm{Cl}=0.77,0.87))$ in Oromia region. In the group analysis, significant heterogeneity was recognized between regions $\left(\mathrm{I}^{2}=99.81, \mathrm{P}<001\right)$ (Figure 4$)$. However, since each region represented only by one or two candidate articles, the results for intragroup heterogeneity remained consistent with the result of pooled prevalence (Figures $2 \& 4$ ).

\section{Sensitivity testing}

Sensitivity analysis was computed through a serial exclusion of each article from meta-analysis to estimate the stability of the pooled effect against decision. Accordingly, though there was no a pretty change on the results two studies, however, have slightly reduced the value [18,48]. To find out the potential source of heterogeneity, further analysis (a univariate Meta regression analysis followed by multivariate analysis) on two variables (year of publication \& sample size) have identified a sample size as a potential source of heterogeneity while year of publication was not (Table 3).

Table 3 Meta regression analysis output on factors associated with heterogeneity of Prevalence of TT among adults in Ethiopia

\begin{tabular}{llll} 
Variables & Coefficient & P-value & {$[95 \% \mathrm{Cl}]$} \\
\hline Year of publication & 518.257 & 0.222 & $-396.025,1432.54$ \\
\hline Sample size & .022 & 0.006 & $0.0085755,0.0357267$ \\
\hline Constant & -1045522 & 0.222 & $-2889310,798266.8$
\end{tabular}

\section{Publication bias}

Publication bias was assessed using a funnel plot that conventionally recommended as a rule of thumb for a minimum of 10 studies in meta-analysis to differentiate real symmetry distribution from occurrence by chance [57]. Consequently, the conduct of the procedure visualized presenting the meta-analysis result containing ten articles that demonstrated a symmetric distribution of the studies along the funnel plot which envisage the absence of evidence of publication bias (Figure 5).

\section{Discussion}

In the current systematic review and meta-analysis, researchers reviewed all published data on the prevalence and determinants of the TT in the adults aged 15 years and above in Ethiopia. During the review, the researchers have recognized the existence of extensive trachoma elimination activities in Ethiopia between 2015 \& 2020[18]. However, the activities did not include extensive data on extensive samples or use a robust study design on the TT determinants. Most of the identified articles were conducted under the lead of local trachoma implementing partners with little involvement of academic institutions, and only cross-sectional study designs were used to identify the prevalence trachoma including TT [18,48-56]. The overall pooled prevalence of the country $(1.80 \%)$ was found to be higher than the international elimination threshold $(<1 \%)$ [7]. particularly, the TT prevalence was about $1.96 \%, 1.7 \%$ and $0.1 \%$ higher than the pooled prevalence in Gamibella, Amhara and national level in respective order than the pooled prevalence. However, TT prevalence in Oromia, Benshangul-gumuz, Afar, Tigray, Somalia and SNNPR was lower than the pooled prevalence. Further, when compared with WHO trachoma elimination threshold that indicated TT prevalence $<1 \%$ per 1000 population, the pooled prevalence surpassed by $0.8 \%[2]$.when compared to other countries, the current pooled results was also higher than study reports in Senegal[58] but lower than study result conducted in Keniya [59].

The position of these variations could be explained by several reasons where the predominant reasons might be theendemicityhistory of trachoma in the area, and current level trachoma intervention activities of particular region [15]. Additionally, the time period of the study could also matters especially in Gamibella and Tigray; meaning, the studies were conducted in the 2016 whereas the implementation activities have been continued to date with paramount reduction of the prevalence. It was also noticed that the prevalence of TT varies among the regions where the possible source of variation was explored to be the sample size. In regards to this variation, though the a design parameters for population based-survey was uniformly endorsed for all trachoma endemic countries, individual country might deploy the design with few modification in reference to topography, general healthcare system, environmental sanitation and characteristics of the study population [60]. Regardless of their variation among the regions, the results have been used for comparison of themomentum of thetrachoma program implementation with reference to the WHO trachoma elimination threshold, and has contributed to elimination activities[18, 48-56]. As the trachoma program guideline indicates, surveys are expected after every six months of trachoma-related activities to control cases of TT and general trachoma elimination activities that could consequently lead to a sufficient number of published articles [22, 41]. However, from the current review, the numbers of studies conducted in the latter years were even lower than the earlier years while the prevalence of TT was at an incoherent increase. As compared to the other regions, the Amhara region published two of the included articles, and recognized as the region where a higher number of researches conducted regardless of the paucity of researches in the country in general[30,33]. This might be related to the higher prevalence of trachoma in the region [63].

The included articles were simultaneously analyzed for all age categories to identify the prevalence of the TT where the condition could be based on different outcomes. All of the articles included were entirely based on the design that relies on the participants $₫$ self- reported responses and can be judged as ontologically inconvenient. Additionally, none of the studies have incorporated laboratory tests for estimation or confirmation of the infection. The review also recognized that most of the articles have missed stating tool validation on outcome measurement, and in most cases, the authors did not provide detail statistical evidence to envisage their findings[18, 48-56].Moreover, studies were conducted at the household level using district as an evaluation unit and generally referred to estimate the prevalence ofTT at the regional level, supportinga decision-making process on whether to continue or stop trachoma intervention activities at the community level. The number of sample size used by the articles during the study werevary across the regions with the minimum sample size of 3781 being in Gambella [48] and the maximum sample size 208,265 in the Amhara region [18].Regardless of similar objectives\& designs among the piloted studies. The standard response rate definition, which is acceptable if the survey is $10-15 \%$, was not reported in the studies included.

Page 6/13 
Similarly, for all included studies, morbidity was the single standing-alone outcome that analyzed while it was possible to visualize the further amount of analysis. However, the reviewed articles have assisted the trachoma elimination activity implementing partners to specify the prevalence of TT in the field and consciously apply respective TT elimination activities $[16,64]$.

\section{Strengths and limitations of the study}

The review was conducted by two reviewers to summarize and made the data ready for use for decision making during the salient time of trachoma elimination. The review has explored all available evidences and included only evidences of good quality. However, the numbers of included studies were deficient with some of the studies missing some important variables in proportion, and consequently, limited the scope computation of certain analysis. Further, following the scare systematic review and meta-analysis on the current thematic area, we have compared the current findings with the results of nonesystematic review and meta-analysis studies.

\section{Conclusions And Recommendations}

Based on the current systematic review and meta-analysis the overall pooled prevalence was higher than the WHO elimination threshold and continued a public health problem in all included regions of Ethiopia. The researchers could also identified that the prevalence of TT entirely varies across regions due to the deployed number of study participants, and the prevalence is poignantly higher than the pooled result in majority of the regions with unstable trend of occurrence. To the scope of the current systematic review and meta-analysis, there was no evidence to define the determinants of TT among the adult population in the study area. Therefore, high-quality research is in need to fully describe the contemporary patterns of trachoma among the adult population in Ethiopia. The researchers also recommend observational studies to explore temporal conditions that influence trachoma elimination and advocate implementers to step in and stop the condition.

\section{Declarations}

Ethical approval and consent to participate: not applicable

Consent for publication: not applicable

Availability of data and materials: All relevant data are within the paper and its supporting information files.

Competing interests: The authors declare that they have no competing interests

Funding: There was no specified source of fund for the included sources of evidence, as well as the scoping review.

Authors' contribution: Both authors (DG \& NW) were equally contributed in conceptualizing, designing, analyzing and reporting of the review.

Acknowledgements: There is no special acknowledgment

\section{Abbreviations}

Cl: Confidence Interval, CBCS: Community-Based Cross-sectional study, ETP: Estimate trachoma prevalence, TF: Follicular inflammation, TT: Trachomatous Trichiasis, WHO: World Health Organization

\section{References}

[1] Amenu K, Getachew T, Bekele A, Defar A, Taddesse M, Teklie H, et al. Neglected Tropical Diseases (NTD) service availability at health facilities in Ethiopia: Evidence from 2014 Ethiopian service provision assessment. EJHD 2017;31.

[2] World Health Organization, Department of Control of Neglected Tropical Diseases. Integrating neglected tropical diseases into global health and development: fourth WHO report on neglected tropical diseases. 2017.

[3] A.W. S, R.W. P, A. F, D.C.W. M. Diagnosis and assessment of trachoma. Clinical Microbiology Reviews 2004;17:982-1011.

https://doi.org/10.1128/CMR.17.4.982.

[4] Solomon AW, Peeling RW, Foster A, Mabey DCW. Diagnosis and Assessment of Trachoma 2004;17:982-1011. https://doi.org/10.1128/CMR.17.4.982.

[5] WHO simplified trachoma grading system. Community Eye Health 2004;17.

[6] Tadesse B, Worku A, Kumie A, Yimer SA. Effect of water, sanitation and hygiene interventions on active trachoma in North and South Wollo zones of Amhara Region, Ethiopia: A Quasi-experimental study. PLoS Neglected Tropical Diseases 2017. https://doi.org/10.1371/journal.pntd.0006080.

[7] Amenu K, Getachew T, Bekele A, Defar A, Taddesse M, Teklie H, et al. Neglected Tropical Diseases (NTD) service availability at health facilities in Ethiopia: Evidence from 2014 Ethiopian service provision assessment. EJHD 2017;31.

[8] World Health Organization. Integrating neglected tropical diseases into global health and development: fourth WHO report on neglected tropical diseases. Geneva: World Health Organization; 2017. 
[9] WHO simplified trachoma grading system - PubMed n.d. https://pubmed.ncbi.nlm.nih.gov/17491830/ (accessed June 10, 2021).

[10] The Causes and Impacts of Neglected Tropical and Zoonotic Diseases: Opportunities for Integrated Intervention Strategies: Workshop Summary. Washington, D.C.: National Academies Press; 2011. https://doi.org/10.17226/13087.

[11] World Health Organization, Department of Control of Neglected Tropical Diseases. Integrating neglected tropical diseases into global health and development: fourth WHO report on neglected tropical diseases. 2017.

[12] Institute of Medicine (US) Forum on Microbial Threats. The Causes and Impacts of Neglected Tropical and Zoonotic Diseases: Opportunities for Integrated Intervention Strategies. Washington (DC): National Academies Press (US); 2011.

[13] Training system for trachoma prevalence surveys | Tropical Data n.d. https://tropicaldata.knowledgeowl.com/help/training- system-for-trachomaprevalence-surveys (accessed June 10, 2021).

[14] CDC - Neglected Tropical Diseases - Global NTD Programs 2020. https://www.cdc.gov/globalhealth/ntd/global_program.html (accessed June 10, 2021).

[15] Asaolu S, Caines K, Crompton D, Diallo A, Ndiaye J, Njie A. Methodology for evaluation of neglected tropical disease control programmes at country level n.d.:65.

[16] World Health Organization. WHO alliance for the global elimination of trachoma by 2020: progress report, 2019. Weekly Epidemiological Record 2020;95:349-60.

[17] Solomon AW, Kello AB, Bangert M, West SK, Taylor HR, Tekeraoi R, et al. The simplified trachoma grading system, amended. Bull World Health Organ 2020;98:698-705. https://doi.org/10.2471/BLT.19.248708.

[18] Stewart AEP, Zerihun M, Gessese D, Melak B, Sata E, Nute AW, et al. Progress to Eliminate Trachoma as a Public Health Problem in Amhara National Regional State, Ethiopia: Results of 152 Population-Based Surveys. The American Journal of Tropical Medicine and Hygiene 2019;101:1286-95. https://doi.org/10.4269/ajtmh.19-0450.

[19] Habīb M. The Ethiopian federal system: the formative stage. Addis Ababa: Friedrich-Ebert-Stiftung; 2011.

[20] Our guidance - Centre for Reviews and Dissemination, University of York n.d. https://www.york.ac.uk/crd/guidance/ (accessed June 14, 2021).

[21] Stroup DF, Berlin JA, Morton SC, Olkin I, Williamson GD, Rennie D, et al. Meta-analysis of observational studies in epidemiology: a proposal for reporting. Meta-analysis Of Observational Studies in Epidemiology (MOOSE) group. JAMA 2000;283:2008-12. https://doi.org/10.1001/jama.283.15.2008.

[22] Moher D, Liberati A, Tetzlaff J, Altman DG, Group TP. Preferred Reporting Items for Systematic Reviews and Meta-Analyses: The PRISMA Statement. PLOS Medicine 2009;6:e1000097. https://doi.org/10.1371/journal.pmed.1000097.

[23] GET2020_2016_EN.pdf n.d. - Google Search n.d. https://www.google.com/search? q=GET2020_2016_EN.pdf+n.d.\&rlz=1C1VDYX_enET888ET888\&oq=GET2020_2016_EN.pd f+n.d.\&aqs=chrome..69i57.1054j0j9\&sourceid=chrome\&ie=UTF-8 (accessed June 19, 2021).

[24] Modesti PA. Cross Sectional Study Newcastle - Ottawa Quality Assessment Scale. PLoS ONE 2016;11:1-2.

[25] D H, P B, A W, F B, L M, C B, et al. Assessing risk of bias in prevalence studies: modification of an existing tool and evidence of interrater agreement. Journal of Clinical Epidemiology 2012;65. https://doi.org/10.1016/j.jclinepi.2011.11.014.

[26] Critical Appraisal Skills Programme (CASP). CASP Checklist: Cohort Study. Casp Uk 2018:7.

[27] Critical Appraisal Skills Programme. CASP Case Control Study Checklist 2018.

[28] Huedo-Medina TB, Sánchez-Meca J, Marín-Martínez F, Botella J. Assessing heterogeneity in meta-analysis: Q statistic or I2 index? Psychol Methods 2006;11:193-206. https://doi.org/10.1037/1082-989X.11.2.193.

[29] Morberg DP, Alemayehu W, Melese M, Lakew T, Sisay A, Zhou Z, et al. A Longitudinal Analysis of Chlamydial Infection and Trachomatous Inflammation Following Mass Azithromycin Distribution. Ophthalmic Epidemiology 2019;26:19-26. https://doi.org/10.1080/09286586.2018.1512635.

[30] Anteneh ZA, Getu WY. Prevalence of active trachoma and associated risk factors among children in Gazegibela district of Wagehemra Zone, Amhara region, Ethiopia: community-based cross-sectional study. Tropical Diseases, Travel Medicine and Vaccines 2016;2:5. https://doi.org/10.1186/s40794-0160022-0.

[31] Oswald WE, Stewart AE, Kramer MR, Endeshaw T, Zerihun M, Melak B, et al. Active trachoma and community use of sanitation, Ethiopia. Bulletin of the World Health Organization 2017;95:250-60. https://doi.org/10.2471/BLT.16.177758.

Page $8 / 13$ 
[32] Durkin SR, Casson R, Newland HS, Selva D. Prevalence of trachoma and diabetes-related eye disease among a cohort of adult Aboriginal patients screened over the period 1999-2004 in remote South Australia. Clinical \& Experimental Ophthalmology 2006;34:329-34. https://doi.org/10.1111/j.14429071.2006.01215.x.

[33] Garn JV, Boisson S, Willis R, Bakhtiari A, Al-Khatib T, Amer K, et al. Sanitation and water supply coverage thresholds associated with active trachoma: Modeling cross-sectional data from 13 countries. PLoS Neglected Tropical Diseases 2018. https://doi.org/10.1371/journal.pntd.0006110.

[34] Yalew KN, Mekonnen MG, Jemaneh AA. Trachoma and its determinants in Mojo and Lume districts of Ethiopia. The Pan African Medical Journal 2012;13 Suppl 1:8.

[35] Flueckiger RM, Giorgi E, Cano J, Abdala M, Amiel ON, Baayenda G, et al. Understanding the spatial distribution of trichiasis and its association with trachomatous inflammation-follicular. BMC Infectious Diseases 2019;19:364. https://doi.org/10.1186/s12879-019-3935-1.

[36] Hiep NX, Ngondi JM, Anh VT, Dat TM, An TV, Dung NC, et al. Trachoma in Viet Nam: results of 11 surveillance surveys conducted with the Global Trachoma Mapping Project. Ophthalmic Epidemiology 2018;25:93-102. https://doi.org/10.1080/09286586.2018.1477964.

[37] Jie Y, Xu L, Ma K, Zhang S, Zhu J, Jonas JB. Prevalence of trachoma in the adult Chinese population.The Beijing Eye Study. Eye (London, England) 2008;22:790-1. https://doi.org/10.1038/sj.eye.6702857.

[38] Muluneh EK, Zewotir T, Bekele Z. Rural children active trachoma risk factors and their interactions. The Pan African Medical Journal $2016 ; 24: 128$. https://doi.org/10.11604/pamj.2016.24.128.8790.

[39] Tadesse B, Worku A, Kumie A, Yimer SA. The burden of and risk factors for active trachoma in the North and South Wollo Zones of Amhara Region, Ethiopia: a cross-sectional study. Infectious Diseases of Poverty 2017;6:143. https://doi.org/10.1186/s40249-017-0358-3.

[40] Kassim K, Kassim J, Aman R, Abduku M, Tegegne M, Sahiledengle B. Prevalence of active trachoma and associated risk factors among children of the pastoralist population in Madda Walabu rural district, Southeast Ethiopia: a community-based cross- sectional study. BMC Infectious Diseases 2019;19:353. https://doi.org/10.1186/s12879-019-3992-5.

[41] Tilahun Z, Fenta TG. Coverage of azithromycin mass treatment for trachoma elimination in Northwestern Ethiopia: a community based cross-sectional study. BMC Ophthalmology 2018;18:193. https://doi.org/10.1186/s12886-018-0868-1.

[42] Ngondi J, Gebre T, Shargie EB, Graves PM, Ejigsemahu Y, Teferi T, et al. Risk factors for active trachoma in children and trichiasis in adults: a household survey in Amhara Regional State, Ethiopia. Transactions of the Royal Society of Tropical Medicine and Hygiene 2008;102:432-8.

https://doi.org/10.1016/j.trstmh.2008.02.014.

[43] Gebrie A, Alebel A, Zegeye A, Tesfaye B, Wagnew F. Prevalence and associated factors of active trachoma among children in Ethiopia: a systematic review and meta-analysis. BMC Infectious Diseases 2019;19:1073. https://doi.org/10.1186/s12879-019- 4686-8.

[44] Nigusie A, Berhe R, Gedefaw M. Prevalence and associated factors of active trachoma among childeren aged 1-9 years in rural communities of Gonji Kolella district, West Gojjam zone, North West Ethiopia. BMC Research Notes 2015;8:641. https://doi.org/10.1186/s13104-015-1529-6.

[45] Ferede AT, Dadi AF, Tariku A, Adane AA. Prevalence and determinants of active trachoma among preschool-aged children in Dembia District, Northwest Ethiopia. Infectious Diseases of Poverty 2017;6:128. https://doi.org/10.1186/s40249-017-0345-8.

[46] Habtamu E, Wondie T, Aweke S, Tadesse Z, Zerihun M, Zewdie Z, et al. Trachoma and Relative Poverty: A Case-Control Study. PLoS Neglected Tropical Diseases 2015;9:e0004228. https://doi.org/10.1371/journal.pntd.0004228.

[47] Regassa K, Teshome T. Trachoma among adults in Damot Gale District, South Ethiopia. Ophthalmic Epidemiology 2004;11:9- 16. https://doi.org/10.1076/opep.11.1.9.26440.

[48] Abashawl A, Macleod C, Riang J, Mossisa F, Dejene M, Willis R, et al. s. Ophthalmic Epidemiology 2016;23:77-83.

https://doi.org/10.1080/09286586.2016.1247875.

[49] Sherief ST, Macleod C, Gigar G, Godefay H, Abraha A, Dejene M, et al. The Prevalence of Trachoma in Tigray Region, Northern Ethiopia: Results of 11 Population-Based Prevalence Surveys Completed as Part of the Global Trachoma Mapping Project. Ophthalmic Epidemiology 2016;23:94-9.

https://doi.org/10.1080/09286586.2016.1250917.

[50] Adamu Y, Macleod C, Adamu L, Fikru W, Kidu B, Abashawl A, et al. Prevalence of Trachoma in Benishangul Gumuz Region, Ethiopia: Results of Seven Population-Based Surveys from the Global Trachoma Mapping Project. Ophthalmic Epidemiology 2016;23:70-6.

https://doi.org/10.1080/09286586.2016.1247877. 
[51] Bero B, Macleod C, Alemayehu W, Gadisa S, Abajobir A, Adamu Y, et al. Prevalence of and Risk Factors for Trachoma in Oromia Regional State of Ethiopia: Results of 79 Population-Based Prevalence Surveys Conducted with the Global Trachoma Mapping Project. Ophthalmic Epidemiology 2016;23:392405. https://doi.org/10.1080/09286586.2016.1243717.

[52] Adera TH, Macleod C, Endriyas M, Dejene M, Willis R, Chu BK, et al. Prevalence of and Risk Factors for Trachoma in Southern Nations, Nationalities, and Peoples $\bigotimes$ Region, Ethiopia: Results of 40 Population-Based Prevalence Surveys Carried Out with the Global Trachoma Mapping Project. Ophthalmic Epidemiology 2016;23:84-93. https://doi.org/10.1080/09286586.2016.1247876.

[53] Negash K, Macleod C, Adamu Y, Ahmed M, Ibrahim M, Ali M, et al. Prevalence of trachoma in the Afar Region of Ethiopia: results of seven populationbased surveys from the Global Trachoma Mapping Project. Ophthalmic Epidemiology 2018;25:3-10. https://doi.org/10.1080/09286586.2017.1362008.

[54] Nash SD, Stewart AEP, Astale T, Sata E, Zerihun M, Gessese D, et al. Trachoma prevalence remains below threshold in five districts after stopping mass drug administration: results of five surveillance surveys within a hyperendemic setting in Amhara, Ethiopia. Transactions of the Royal Society of Tropical Medicine and Hygiene 2018;112:538-45. https://doi.org/10.1093/trstmh/try096.

[55] Duale AB, Negussu Ayele N, Macleod CK, Kello AB, Eshetu Gezachew Z, Binegdie A, et al. Epidemiology of trachoma and its implications for implementing the "SAFE" strategy in Somali Region, Ethiopia: results of 14 population-based prevalence surveys. Ophthalmic Epidemiology 2018;25:25-32. https://doi.org/10.1080/09286586.2017.1409358.

[56] Macleod CK, Porco TC, Dejene M, Shafi O, Kebede B, Negussu N, et al. Optimising age adjustment of trichiasis prevalence estimates using data from 162 standardised surveys from seven regions of Ethiopia. Ophthalmic Epidemiology 2019;26:161-8. https://doi.org/10.1080/09286586.2018.1555262.

[57] Higgins JPT, Green S, Cochrane Collaboration, editors. Cochrane handbook for systematic reviews of interventions. Chichester, England ; Hoboken, NJ: Wiley-Blackwell; 2008.

[58] Population-based prevalence survey of follicular trachoma and trachomatous trichiasis in the Casamance region of Senegal | www.trachomacoalition.org n.d. https://www.trachomacoalition.org/resources/population-based-prevalence-survey-follicular- trachoma-and-trachomatoustrichiasis (accessed June 19, 2021).

[59] Schwab L, Whitfield R, Ross-Degnan D, Steinkuller P, Swartwood J. The epidemiology of trachoma in rural Kenya.Variation in prevalence with lifestyle and environment. Study Survey Group. Ophthalmology 1995;102:475-82. https://doi.org/10.1016/s0161-6420(95)30997-9.

[60] Organization WH. Design parameters for population-based trachoma prevalence surveys: strategic and technical advisory group for neglected tropical diseases, working group on monitoring and evaluation 2018.

[61] SNV in Ethiopia develops a Trachoma Programming Strategy I SNV World n.d. https://snv.org/update/snv-ethiopia-develops- trachoma-programmingstrategy (accessed April 16, 2021).

[62] A.W. S, R.W. P, A. F, D.C.W. M. Diagnosis and assessment of trachoma. Clinical Microbiology Reviews 2004;17:982-1011.

https://doi.org/10.1128/CMR.17.4.982.

[63] Gebrie A, Alebel A, Zegeye A, Tesfaye B, Wagnew F. Prevalence and associated factors of active trachoma among children in Ethiopia: a systematic review and meta-analysis. BMC Infectious Diseases 2019;19:1073. https://doi.org/10.1186/s12879-019- 4686-8.

[64] WHO | Integrating neglected tropical diseases in global health and development n.d.

https://www.who.int/neglected_diseases/resources/9789241565448/en/ (accessed June 10, 2021).

\section{Figures}




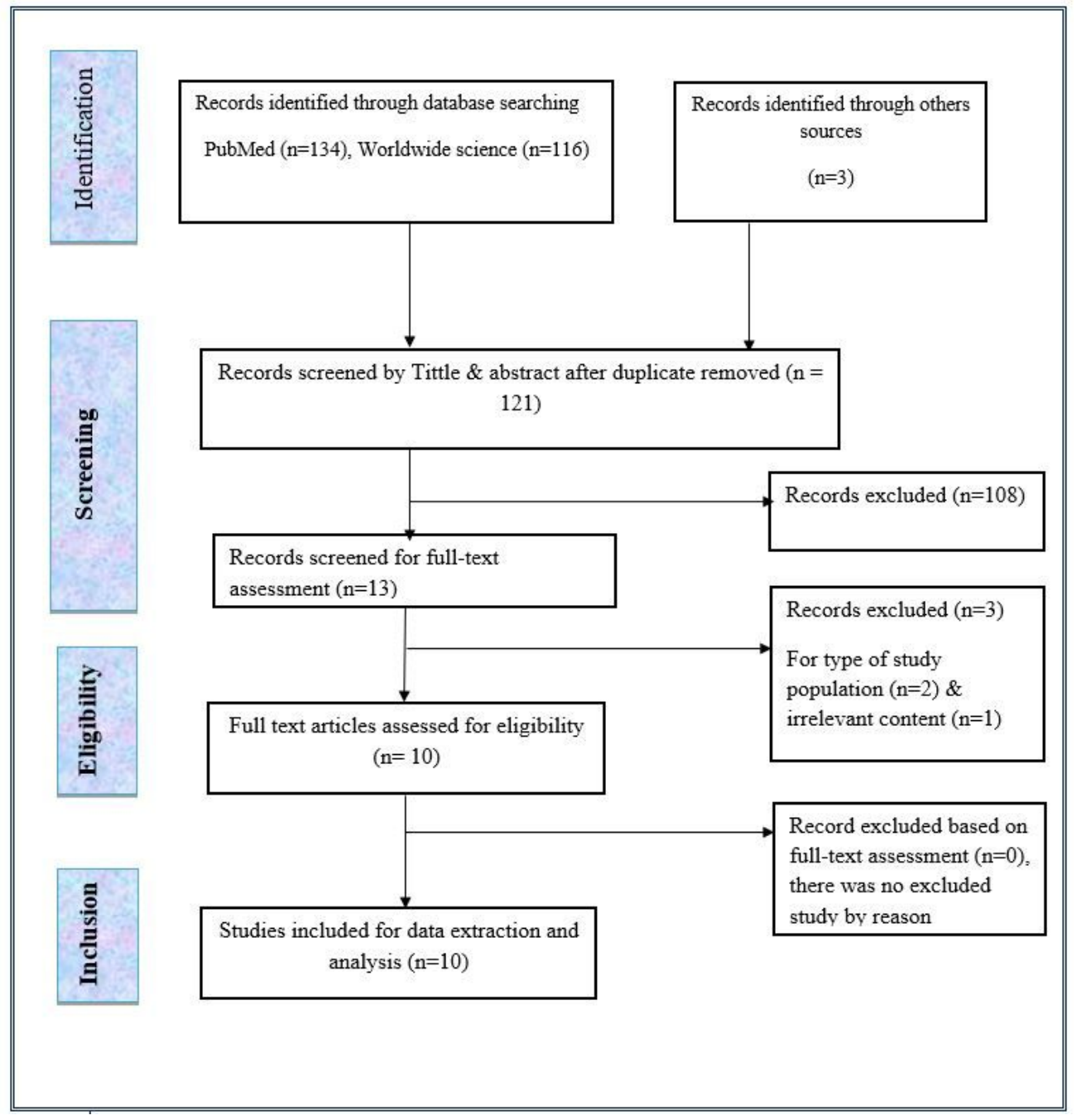

Figure 1

PRISMA flow chart to illustrate the process by which articles were selected or rejected




Figure 2

forest plot of the pooled TT prevalence among 15 year \& older population in Ethiopia

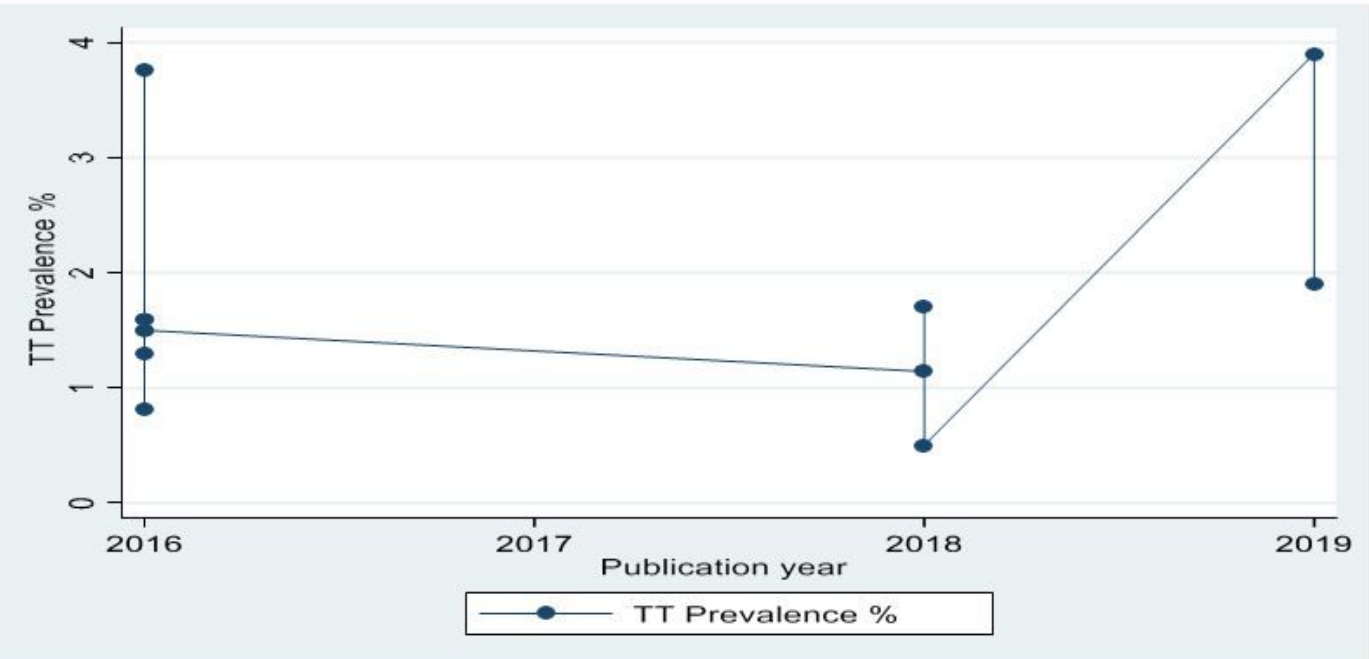

Figure 3

Patterns of TT prevalence through 2015 to 2020 year of publication among adult population in Ethiopia



\section{Figure 4}

Subgroup analysis of TT prevalence by region in Ethiopia 


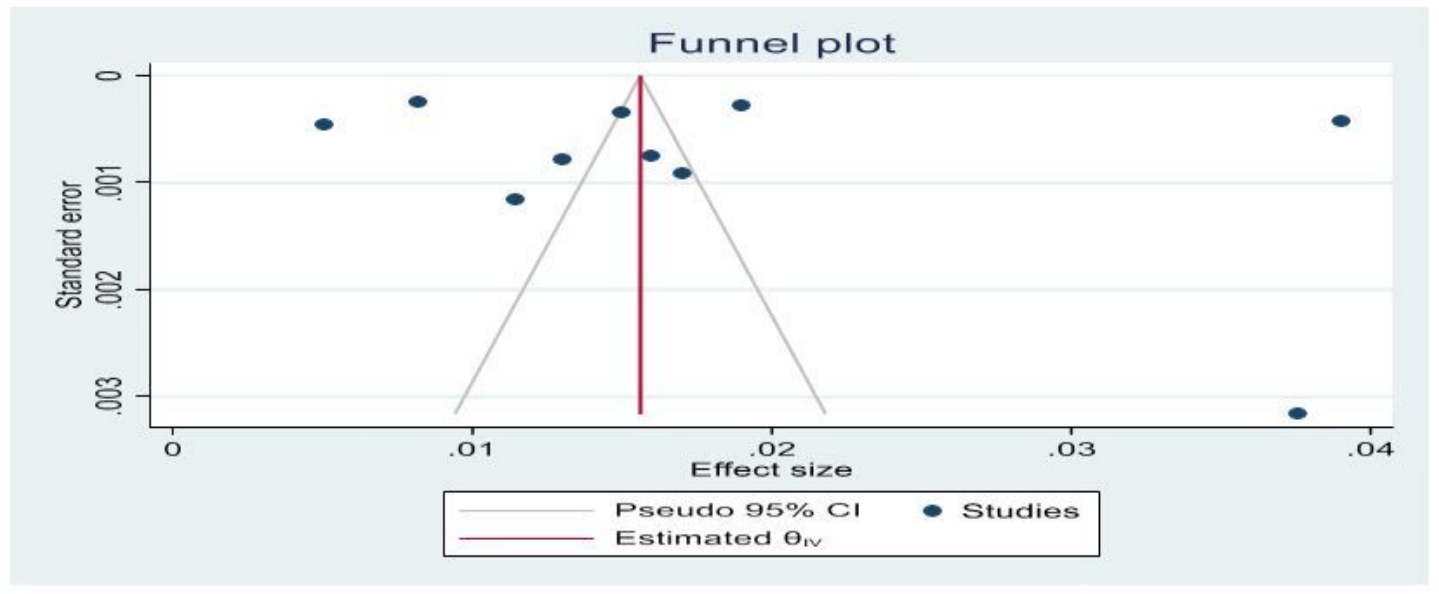

Figure 5

funnel plot of meta-analysis output for ten included studies 